\title{
QUE CRÍTICAS DA TEORIA DO DIREITO COMO INTEGRIDADE DE DWORKIN PODE FAZER CONTRA A TESE DO LIVRE CONVENCIMENTO MOTIVADO DO MAGISTRADO?
}

\author{
WHAT CRITICISMS DWORKIN'S LAW AS INTEGRITY THEORY CAN MAKE \\ AGAINST THE THESIS OF FREE MOTIVATION OF THE JUDICIAL \\ ADJUDICATION?
}

\section{¿QUÉ CRÍTICAS DE LA TEORÍA DEL DERECHO COMO INTEGRIDAD DE DWORKIN PUEDE HACER CONTRA LA TESIS DEL LIBRE CONVENCIMIENTO MOTIVADO DEL MAGISTRADO?}

\author{
FLÁvio Quinaud PEDRON
}

https://orcid.org/0000-0003-4804-2886 / http://lattes.cnpq.br/4259444603254002 / qpedron@gmail.com

Doutor e Mestre em Direito pela Universidade Federal de Minas Gerais (UFMG). Professor Adjunto do Mestrado em Direito e da Graduação da Faculdade Guanambi (Bahia). Professor Adjunto da PUC-Minas (Graduação e Pósgraduação). Professor Adjunto do IBMEC. Editor-Chefe da Revista de Direito da Faculdade Guanambi. Membro do Instituto Brasileiro de Direito Processual (IBDP). Membro da Associação. Advogado. Guanambi, BA, Brasil.

\begin{abstract}
RESUMO
O presente texto pretende demonstrar a insustentabilidade de uma visão tradicional dentro da Teoria Geral do Processo capaz de defender a permanência de mero e insuficiente dever de motivação das decisões judiciais. Sendo assim, fazendo uso de uma metodologia voltada para a revisão de literatura a respeito, a partir de uma reconstrução histórico-crítica, apresenta-se a problemática leitura da tese do livre convencimento motivado, a partir de uma relação de adesão a uma teoria processual não democrática. Assim, é observado que a função da motivação é presa a uma leitura hermenêutica inconsciente quanto à ocorrência do giro linguístico e apegada a um paradigma positivista jurídico. Em seguida, usando os recursos teóricos fornecidos pela Teoria do Direito como Integridade de Ronald Dworkin, demonstra-se como o paradigma processual democrático pode ser compreendido adequadamente, superando, simultaneamente, uma Teoria do Direito Positivista, bem como uma teoria do processo não democrática. A consequência direta é a superação da ideia de motivação e sua substituição para a compreensão do que é um provimento jurisdicional fundamentado.
\end{abstract}

Palavras-chave: Livre Convencimento Judicial; Ronald Dworkin; Teoria do Direito como Integridade.

\begin{abstract}
The present text demonstrates the unsustainability of a traditional view within the General Theory of the Process capable of defending the permanence of mere and insufficient duty of motivation of judicial decisions. Thus, using a methodology aimed at reviewing literature on the subject, based on a critical historical reconstruction, we present the problematic reading of the thesis of free convincing motivated, based on a relation of adherence to an undemocratic procedural theory. Thus, it will be observed that the function of motivation is bound to an unconscious hermeneutic reading as to the occurrence of linguistic turn and attached to a positivist legal paradigm. Then, using the theoretical resources provided by Ronald Dworkin's Theory of Law as Integrity, we demonstrate how the democratic procedural paradigm can be properly understood, overcoming both a Positivist Law Theory as well as an undemocratic process. The direct consequence is the overcoming of the idea of motivation and its substitution for the understanding of what is a justified judicial provision.
\end{abstract}

Keywords: Free Judicial Conviction; Ronald Dworkin; Theory of Law as Integrity. 

DWORKIN PODE FAZER CONTRA A TESE DO LIVRE CONVENCIMENTO MOTIVADO DO MAGISTRADO?

\section{RESUMEN}

El presente texto presente demostrar la insostenibilidad de una visión tradicional dentro de la Teoría General del Proceso capaz de defender la permanencia de mero e insuficiente deber de motivación de las decisiones judiciales. Siendo así, haciendo uso de una metodología orientada a la revisión de literatura al respecto, a partir de una reconstrucción histórica crítica, presentamos la problemática lectura de la tesis del libre convencimiento motivado, a partir de una relación de adhesión a una teoría procesal no democrática. Así, se observará que la función de la motivación es presa a una lectura hermenéutica inconsciente en cuanto a la ocurrencia del giro lingüístico y apegada al un paradigma positivista jurídico. A continuación, usando los recursos teóricos proporcionados por la Teoría del Derecho como Integridad de Ronald Dworkin, demostramos cómo el paradigma procesal democrático puede ser comprendido adecuadamente, superando al mismo tiempo una Teoría del Derecho Positivista, así como una tendría del proceso no democrático. La consecuencia directa es la superación de la idea de motivación y su sustitución para la comprensión de lo que es una provisión jurisdiccional fundamentada.

Palabras clave: Libre Convencimiento Judicial; Ronald Dworkin; Teoría del Derecho como Integridad.

\section{SUMÁRIO}

INTRODUÇÃO; 1 A TEORIA DO LIVRE CONVENCIMENTO NO CENÁRIO DA TEORIA GERAL DO PROCESSO TRADICIONAL; 2 FUNDAMENTAÇÃO E BUSCA PELA RESPOSTA CORRETA COMO PRESSUPOSTOS HERMENÊUTICOS À LUZ DA TEORIA DO DIREITO COMO INTEGRIDADE DE RONALD DWORKIN CONTRÁRIOS À TESE DO LIVRE CONVENCIMENTO; CONCLUSÃO; REFERÊNCIAS.

\section{INTRODUÇÃO}

Ainda parece saltar aos olhos o modo e a forma com a qual a Teoria Geral do Processo parece compreender a figura do livre convencimento motivado. Mesmo sob as luzes normativas da Constituição Federal (CF) de 1988, que em seu art. 93, IX, fixa as exigências de fundamentação dos provimentos jurisdicionais, ainda não são poucas as vozes que sinalizam para uma confusão epistemológica entre o que vem a ser o ato de motivação e uma fundamentação adequada. $^{1}$

Acredita-se que a raiz para tal problema decorra, antes de tudo, de uma dificuldade, de um lado, por parte dos membros da Teoria Geral do Processo tradicional serem capazes de perceber o esgotamento do paradigma ${ }^{2}$ teórico da teoria relacionista do processo ${ }^{3}$ - ou de sua

\footnotetext{
1 Apenas para mencionar alguns nomes que ainda endossam essa leitura, que procura-se demonstrar ultrapassada e equivocada, cita-se: BUENO, Cassio Scarpinella. Curso Sistematizado de Direito Processual Civil: Teoria Geral do Direito Processual Civil. 7. ed. São Paulo: Saraiva, 2013. v. 1.; DIDIER JR., Fredie; BRAGA, Paula Sarno; OLIVEIRA, Rafael Alexandria. Curso de Direito Processual Civil. 11. ed. Salvador: JusPodivm, 2016. v. 2.; SANTOS, Eduardo Rodrigues dos. Princípios Processuais Constitucionais. Salvador: JusPodivm, 2016; e ZUFELATO, Camilo. Fundamentação lógica das decisões judiciais. In: THEODORO JR., Humberto; CALMON, Petrônio; NUNES, Dierle (Coord.). Processo e Constituição. Rio de Janeiro: GZ, 2011.

${ }^{2}$ KUHN, Thomas S. A estrutura das revoluções científicas. 6. ed. Trad. Beatriz Vianna Boeira e Nelson Boeira. São Paulo: Perspectiva, 2001. (Coleção Debates, n. 115).

${ }^{3}$ Para uma crítica mais detalhada convida-se a leitura da obra: FERNANDES, Bernardo Gonçalves; PEDRON, Flávio Quinaud. O Poder Judiciário e(m) Crise. Rio de Janeiro: Lumen Juris, 2008.
} 
versão potencializada em terra brasilis, a teoria instrumentalista do processo ${ }^{4}$, muito divulgada por autores como Cândido Rangel Dinamarco; e de outro, pela ainda adesão à tradição do Positivismo Jurídico.

O aspecto negativo de tal miopia paradigmática, parece, na verdade, sinalizar para o enfraquecimento daquilo que Hesse denominava por força normativa da Constituiçãa $0^{5}$; afinal, as discussões - e, principalmente, a resistência por parte dos membros da magistratura brasileira à norma constitucional - somente ganharam mais relevância e espaço nos fóruns de discussões jurídicas a partir da entrada do Código de Processo Civil (CPC)/2015, que em seu art. 489, \$1 , estabelece parâmetros a partir de condutas negativas (ou seja, a legislação fixa exemplos de decisões que não observam a exigência normativa principiológica para demarcar os contornos de uma fundamentação suficientemente democrática).

Desta feita, o presente texto pretende exatamente demonstrar a insustentabilidade de uma visão tradicional dentro da Teoria Geral do Processo ${ }^{6}$ que ainda é capaz de advogar a permanência de um mero dever de motivação das decisões judiciais, o que se refuta e se entende por completo uma decorrência de uma paralisia paradigmática, por parte desses juristas que não foram capazes de abraçar as exigências democráticas trazidas, quer pela Constituição de 1988, quer pelo CPC/2015; principalmente, neste último caso, teimando - ou talvez ignorando - a sobrevivência de um paradigma de teoria processual já em esgotamento.

Sendo assim, fazendo uso de uma metodologia voltada para a revisão de literatura a respeito, a partir de uma reconstrução histórico-crítica, inicia-se por apresentar e por explicar a problemática leitura do que seja o livre convencimento motivado, a partir de uma relação de pertencimento a uma teoria processual não democrática - qual seja a teoria relacionista do processo ou a teoria instrumentalista do processo. Aqui, pode ser observado que a função da motivação ainda é muito presa a uma leitura hermenêutica ${ }^{7}$ que se mostra inconsciente quanto à ocorrência do giro linguístico e também ainda apegada a um paradigma positivista quanto à Teoria do Direito.

\footnotetext{
${ }^{4}$ DINAMARCO, Cândido Rangel. A Instrumentalidade do Processo. 14. ed. São Paulo: Malheiros, 2009.

${ }^{5}$ HESSE, Konrad. A força normativa da Constituição. Trad. Gilmar Ferreira Mendes. Porto Alegre: Sergio Antonio Fabris, 1991.

${ }^{6}$ CINTRA, Antônio; GRINOVER, Ada; DINAMARCO, Cândido. Teoria Geral do Processo. 19. ed. São Paulo: Malheiros, 2003.

7 GADAMER, Hans-Georg. Verdade e Método: Fundamentos de uma hermenêutica filosófica. 7 ed. Trad. Enio Paulo Giachini. Petrópolis: Vozes, 2005.
} 
Em seguida, usando os recursos teóricos fornecidos pela Teoria do Direito como Integridade de Ronald Dworkin ${ }^{8}$, pretende-se demonstrar como um paradigma processual democrático pode ser compreendido adequadamente, superando, simultaneamente, uma Teoria do Direito sob as bases do Positivismo Jurídico, bem como livre de uma leitura relacionista do processo. A consequência direta é a superação da ideia de motivação, como elemento persuasivo democrático suficiente para 0 atendimento das exigências normativas de um modelo constitucional de processo democrático ${ }^{9}$, proposta, em substituição, a correta compreensão do que vem a ser um provimento fundamentado, tanto à luz de uma teoria hermenêutica quanto processual democrática $^{10}$, haja vista que para perspectiva teórica, a decisão judicial sempre tem que se pautar na exigência normativa de busca pela resposta correta para o caso sub judice.

\section{A TEORIA DO LIVRE CONVENCIMENTO MOTIVADO NO CENÁRIO DA TEORIA GERAL DO PROCESSO TRADICIONAL}

Conforme afirmado anteriormente, é possível dizer que há uma estreita linha de raciocínio entre a Crise do Positivismo Jurídico ${ }^{11}$ e a abertura e liberação para que magistrados, em geral, escapando das "amarras da lei”, acabem por construir uma Teoria Geral do Processo a partir de um solipsismo do julgador ${ }^{12}$.

Isso porque, nesse momento de crise, tem-se que os julgadores usurparam a condição de "donos dos sentidos do direito" ${ }^{13}$, passando a julgar de modo solipsista (o termo alemão Selbstsüshtiger, que quer dizer "egoísta”, bem expressa essa ideia). Com isso, corre-se o risco de perda da racionalidade e, como consequência, da legitimidade das decisões judiciais, já que para produção de decisões, o magistrado deveria apoiar-se mais em um "bom senso" ou em um

\footnotetext{
${ }^{8}$ DWORKIN, Ronald. O Império do Direito. Trad. Jefferson Luiz Camargo. São Paulo: Martins Fontes, 1999. (Direito e Justiça).

9 ANDOLINA, Ítalo; VIGNERA, Giuseppe. II modelo costituzionale del processo civile italiano - corso di lesioni. Torino: Giappichelli, 1990.

10 THEODORO JR., Humberto; NUNES, Dierle; BAHIA, Alexandre; PEDRON, Flávio. Novo CPC: Fundamentos e Sistematização. 3. ed. Rio de Janeiro: Forense, 2016.

11 Para mais detalhes sobre a Crise do Positivismo Jurídico, sugere-se a leitura de: PEDRON, Flávio Quinaud. Mutação constitucional e crise do positivismo jurídico. Belo Horizonte: Arraes, 2012.

12 THEODORO JR., Humberto; NUNES, Dierle; BAHIA, Alexandre; PEDRON, Flávio. Novo CPC: Fundamentos e Sistematização. 3. ed. Rio de Janeiro: Forense, 2016. p. 329.

13 SCHMITZ, Leonad Ziesemer. Fundamentar para Decidir: a crise na construção de respostas no processo civil. São Paulo: Revista dos Tribunais, 2015.
} 

DWORKIN PODE FAZER CONTRA A TESE DO LIVRE CONVENCIMENTO MOTIVADO DO MAGISTRADO?

FLÁVIO QUINAUd PEDRON

"sentimento pessoal de justiça", como defendido à época por Calamandrei ${ }^{14}$. Historicamente, tal cenário de superação da noção de que a atividade de aplicação/julgamento é mais do que um mero silogismo lógico, traz consigo uma consequência importante: a reprodução da comunicação jurídica migra da centralidade de um legislador para a pluralidade difusa dos magistrados. Assim, libertos do dever de apenas decidirem a partir das opções dadas pela moldura do direito, inicia-se um movimento que busca compreender a sentença como expressão de um ato de “vontade"15. Daí decorre a noção, já presente em Bülow ${ }^{16}$, de permissão para a discricionariedade judicial; o que de nada tem de diferente das repetidas afirmações de que o provimento jurisdicional está atrelado ao "sentire" do decididor".

Nossas obras clássicas de Teoria Geral do Processo (TGP) ${ }^{18}$ enxergam com naturalidade uma liberdade de convicção do magistrado, que pode, por exemplo, apreciar as provas dos autos a partir de juízos de valoração que ele construiu para si subjetivamente (solipsistamente), sem que seja algo partilhado linguisticamente com os demais sujeitos do processo. Isso porque, infelizmente, nossa TGP tradicional não percebe que há ontologicamente uma distinção entre o ato de motivar e o ato de fundamentar, muitas vezes tratando ambos como sinônimos de maneira superficial ${ }^{19}$. Isso deixa evidenciar que aos mesmos escapa uma preocupação com a construção de uma base hermenêutica adequadamente capaz de transcender o Positivismo Jurídico ${ }^{20}$ como condição para fomentar uma visão democraticamente correta.

${ }^{14}$ CALAMANDREI, Pietro. Eles os juízes, vistos por nós um advogado. São Paulo: Martins Fontes, 1995. p. 149.

15 THEODORO JR., Humberto; NUNES, Dierle; BAHIA, Alexandre; PEDRON, Flávio. Novo CPC: Fundamentos e Sistematização. 3. ed. Rio de Janeiro: Forense, 2016. p. 329.

${ }_{16}$ BÜLOW, Oskar Von. Gesetz und richteramt. Juristiche Zeitgeschichte. Berlim: Berliner Wissenschafts, 2003. p. 37.

17 CARNELUTTI, Francesco. Diritto e processo. Napoli: Morano, 1958. O curioso é que pesa um erro de tradução do latim por tais juristas: sentire, na verdade, vem significar ouvir/escutar, e não necessariamente sentir, como bem explica ABBOUD, Georges. Discricionariedade: alcance da atuação administrativa e judicial no Estado Constitucional. 2013. Tese (Doutorado em Direito) - Pontifícia Universidade Católica de São Paulo, São Paulo, 2013. p. 549.

${ }^{18}$ CINTRA, Antônio; GRINOVER, Ada; DINAMARCO, Cândido. Teoria Geral do Processo. 19. ed. São Paulo: Malheiros, 2003. p. 67-68; Como caso da obra DIDIER JR., Fredie; BRAGA, Paula Sarno; OLIVEIRA, Rafael Alexandria. Curso de Direito Processual Civil. 11. ed. Salvador: JusPodivm, 2016. v. 2. p. 105-106, nos estranha ora esta afirmar que a noção de "livre convencimento" foi extirpada do CPC/2015, mas ao mesmo tempo afirmar que a mesma Lei consagra a visão tradicional brasileira de livre valoração das provas, sem perceber a contradição em ambas as afirmações.

19 BUENO, Cassio Scarpinella. Curso Sistematizado de Direito Processual Civil: Teoria Geral do Direito Processual Civil. 7. ed. São Paulo: Saraiva, 2013. v. 1; SANTOS, Eduardo Rodrigues dos. Princípios Processuais Constitucionais. Salvador: JusPodivm, 2016.

${ }^{20}$ Para um autor clássico, como Santos (SANTOS, Moacyr Amaral. Primeiras linhas de direito processual civil. 22. ed. São Paulo: Saraiva, 2008. v. 3. p. 9-11), o ato de decisão é a realização de um raciocínio silogístico pelo qual o magistrado, ao identificar na norma dada uma premissa maior, na situação fática apresentada uma premissa menor, chega por meio da sua decisão à dedução lógica de uma conclusão. 

DWORKIN PODE FAZER CONTRA A TESE DO LIVRE CONVENCIMENTO MOTIVADO DO MAGISTRADO?

Assim, nossa TGP se limita a compreender que a atividade de motivar uma decisão equivale ao ato de fornecer razões para justificar e, com isso, limitar/disciplinar o arbítrio do juiz diante do seu processo de tomada de decisão ${ }^{21}$. No entanto, a consideração recorrente de que se trata de obrigação óbvia faz crer que qualquer motivo apresentado pelo juiz seria suficiente para o cumprimento da norma prevista no art. 93, IX, da CF/1988. Ocorre que, como pontua Ramires:

[...] é preciso diferenciar a fundamentação válida de suas simulações. Fundamentar validamente não é explicar a decisão. A explicação só confere à decisão uma falsa aparência de validade. 0 juiz explica, e não fundamenta, quando diz que assim decide por ter incidido ao caso "tal ou qual norma legal". A atitude do juiz que repete o texto normativo que the pareceu adequado, sem justificar a escolha, não vai além do que faria se não explicitasse de forma alguma o motivo da decisão. Diz Streck que "jamais uma decisão pode ser do tipo 'Defiro com base na lei x ou na súmula y'”. Essa escolha "livre" de sentido não fundamenta 0 julgado, a não ser para alguém ainda tão imerso no paradigma racionalista que acredite que a lei tenha um sentido unívoco e pressuposto. Ao juiz contemporâneo não pode bastar, ao dar cabo a uma discussão, a mera declaração do vencedor, repetindo as razões deste como quem enuncia uma equação matemática. Ao contrário, é preciso que o julgador, no mesmo passo em que diz por que acolheu as razões do vencedor, afirme as razões pelas quais rejeitara a interpretação dada pela parte sucumbente. ${ }^{22}$

Ou seja, a motivação seria o apontamento pelo juiz dos elementos que ele - de modo individual e solitário - considerou mais relevantes no caso e que fizeram que ele tomasse tal decisão em determinado sentido - e não em outro. A TGP escapa a ideia exatamente de abertura dialógica - inerente a uma leitura contemporânea de contraditório - que é exigida na fundamentação, por meio da qual deverá o magistrado convencer as partes e a sociedade da correção de sua decisão. ${ }^{23}$ Nesse sentido, afirma Ommati:

21 TARUfFO, Michele. La Motivación de la Sentencía Civil. Trad. Lorenzo Córdova Vianello. Madrid: Trotta, 2011. e ALISTE SANTOS, Tomás-Javier. La motivación de las resoluciones judiciales. Madrid: Marcial Pons, 2011.

22 RAMIRES, Maurício. Crítica à aplicação dos precedentes no direito brasileiro. Porto Alegre: Livraria do Advogado, 2010. p. 41-42.

${ }^{23}$ PEDRON, Flávio Quinaud. A distinção entre legislação e jurisdição no pensamento de Klaus Günther. Revista da CEJ, Brasília, ano XII, n. 41, abr./jun. 2008. p. 63-64: "O juiz desempenha um papel de terceiro observador do conflito: cabe a ele questionar a coerência das interpretações levantadas pelos participantes (autor e réu) sobre o caso e sobre a norma adequada. Dessa forma, a decisão não é apenas sua, mas uma construção conjunta que deve ainda se voltar para a sociedade, uma vez que esta é a real titular do sistema coerente de normas válidas (e por ele atingida) representado pelo Direito. Uma decisão pode ser considerada fundamentada quando, além de demonstrar a reconstrução argumentativa dos acontecimentos relevantes do caso concreto, explicita a norma adequada a servir de justificativa para a ação singular. Essa decisão, então, não é apenas dirigida aos litigantes, mas a toda a sociedade". 

DWORKIN PODE FAZER CONTRA A TESE DO LIVRE CONVENCIMENTO MOTIVADO DO MAGISTRADO?

Nesse sentido, a fundamentação deve explicar as razões pelas quais o Judiciário aceita ou rejeita determinada interpretação e compreensão do e sobre o Direito estabelecida pelo cidadão. A fundamentação não serve para estabelecer o que determinado juiz, desembargador ou ministro acha sobre o Direito. Isso é motivação, algo irrelevante para o Direito democrático. A fundamentação tem como objetivo fixar a decisão juridicamente correta e, portanto, prescinde das posições pessoais dos magistrados. Da mesma forma, a partir da constitucionalização do Direito fundamental à fundamentação, não se pode mais falar em livre convicção motivada ou em decidir conforme a própria consciência, como muitos juízes e doutrinadores ainda teimam em fazer. ${ }^{24}$

Assim, para a TGP, que ainda reduz a fundamentação à ideia de motivação, tal exigência seria mais relevante para a parte sucumbente, já que seria ela a interessada em atacar a decisão em sede recursal. ${ }^{25}$ Há, ainda, outros posicionamentos teóricos nacionais, que tentam indicar que a motivação teria uma razão de ordem pública, na medida em que, através da sua leitura, seria possível detectar qualquer quebra do requisito jurisdicional da imparcialidade. Ou, como afirma Bueno $^{26}$, a presença da motivação em uma decisão judicial permitiria os demais sujeitos do processo - e também a sociedade - um controle fraco da discricionariedade judicial. Lembra Ommati que o Supremo Tribunal Federal (STF) já enfrentou esse tema e produziu importante decisão através do voto do Min. Gilmar Mendes no RE 434.059/DF, em 2008:

Em um primeiro momento, o STF acertadamente decidiu que o Judiciário deve responder a todos os argumentos levantados pelas partes. O Ministro Gilmar Mendes, em seu voto, com base em clássicos do Direito brasileiro, tais como João Barbalho e Pontes de Miranda, e fazendo menção ao Direito alemão, afirmará que a Constituição de 1988, ao estabelecer os direitos ao contraditório, ampla defesa e devido processo legal, constitucionalizou uma pretensão à tutela jurídica que envolve não só o direito de manifestação e o direito de informação sobre o objeto do processo, mas também o direito de ver os seus argumentos contemplados pelo órgão incumbido de julgar. Sobre esse último aspecto, afirmou o Ministro Gilmar Mendes que o direito de ver os seus argumentos contemplados pelo órgão julgador corresponde ao dever do juiz de a eles conferir atenção, envolvendo não só o dever de tomar conhecimento, como também o de considerar, séria e detidamente, as razões apresentadas. ${ }^{27}$

\footnotetext{
${ }^{24}$ OMMATI, José Emílio Medauar. A fundamentação das decisões jurisdicionais no projeto do Novo Código de Processo Civil. In: FREIRE, Alexandre; DANTAS, Bruno; NUNES, Dierle; DIDIER JR., Fredie et al. Novas tendências do processo civil: estudos sobre o projeto do Novo Código de Processo Civil. Salvador: JusPodivm, 2014. v. III. p. 109.

${ }^{25}$ ASSUMPÇÃO NEVES, Daniel Amorim. Manual de direito processual civil. São Paulo: Método, 2009. p. 62.

${ }^{26}$ BUENO, Cássio Scarpinella. Curso sistematizado de direito processual civil. Teoria geral do direito processual civil. 4. ed. São Paulo: Saraiva, 2010. v. 1. p. 166.

27 OMMATI, José Emílio Medauar. A fundamentação das decisões jurisdicionais no projeto do Novo Código de Processo Civil. In: FREIRE, Alexandre; DANTAS, Bruno; NUNES, Dierle; DIDIER JR., Fredie et al. Novas tendências do processo civil: estudos sobre o projeto do Novo Código de Processo Civil. Salvador: JusPodivm, 2014. v. III. p. 110.
} 
Esse é um entendimento recorrente igualmente no sistema alemão, em conformidade com o dever de se levar em consideração os argumentos das partes, corolário do contraditório (previsto no art. 486, § 1. $\left.{ }^{\circ}, \mathrm{IV}, \mathrm{CPC} / 2015\right)$, como pontua decisão recente do Bundesfinanzhof.

Esse panorama histórico, conseguinte, ensina que a possibilidade de decisões solipsistas tem um outro efeito colateral de fundo sistêmico: o enfraquecimento da segurança jurídica (entendida como previsibilidade decisória). Ora, o sistema do Direito existe para fornecer para a sociedade, na ótica de uma teoria sociológica do direito, um padrão de definição do que seja lícito/ilícito, capaz de valorar as condutas sociais sob a base desse binômio. Uma vez que se assiste o desenvolvimento de decisões sem qualquer coerência ou integridade, o Direito assume a metáfora de uma "mesa de bilhar", na qual decisões seguem cursos diversos e sem harmonização, inclusive criando colisões umas com as outras. O resultado é a perda de normatividade do Direito perante a sua sociedade, o que abre espaços para que outros sistemas, de modo oportunista, acabem tomando espaço, utilizando-se de uma corrupção do código jurídico para impor os seus imperativos. Assim, razões de ordem econômica (meramente utilitárias) ou religiosas (que trazem a promessa de salvação transcendente a partir de um ponto de vista individual excludente) ganham força no conteúdo das tomadas de decisões institucionais. E tudo isso acaba por gerar um ciclo vicioso. Mais e mais o discurso religioso fundamenta práticas e decisões jurídicas (legislativas ou judiciais), bem como direitos (principalmente os fundamentais) são tratados utilitariamente a uma perspectiva de custo/benefício, sendo fragilizados, principalmente aqueles que deveriam proteger uma minoria dos abusos e intervenções de uma maioria. A Jurisdição e os magistrados correm o risco de deixar de assumir, a partir do debate processual, um papel contramajoritário e passam a ser caixa de ressonância dos grupos hegemônicos.

Assim, é preciso superar a ideia de que a decisão judicial é vista como ato de criação solitária pelo magistrado. Essa premissa equivocada agora foi corrigida normativamente pelo $\mathrm{CPC} / 2015$. É dizer, ao contrário do que possa parecer a uma leitura menos atenta, que a fundamentação substancial é solução (e não empecilho) e, para isso, no entanto, há que ser formado como resposta às questões postas, de ambos os lados do debate processual. Com isso, não se poderia desconhecer que a redução da fundamentação das decisões à mera motivação pelo magistrado poderia tão somente reforçar, mais uma vez, a velha tese do "livre convencimento" do juiz, que, sob o argumento de decidir conforme a sua própria consciência, colocaria em risco não apenas a validade, mas a eficiência e a legitimidade da decisão. ${ }^{28}$ Como bem expõe Ommati,

${ }^{28}$ STRECK, Lenio Luiz. 0 que é isto: decido conforme minha consciência? Porto Alegre: Livraria do 
inspirado em Fazzalari,

se o contraditório significa o direito daquele que será atingido pela decisão a participar da construção da mesma, logo, o órgão responsável por tomar a decisão deve fundamentá-la, justamente para explicar os acertos e equívocos dos interessados na construção do Direito. ${ }^{29}$

Logo, de um lado, a busca da eficiência e o máximo aproveitamento processual; de outro, uma teoria da fundamentação das decisões judiciais não desgarrada de uma teoria hermenêutica ou mesmo da argumentação jurídica, o que vem a ser o objeto do próximo tópico do presente texto.

\section{FUNDAMENTAÇÃO E BUSCA PELA RESPOSTA CORRETA COMO PRESSUPOSTOS HERMENÊUTICOS À LUZ DA TEORIA DO DIREITO COMO INTEGRIDADE DE RONALD DWORKIN CONTRÁRIOS À TESE DO LIVRE CONVENCIMENTO}

Uma vez que, com o advento do CPC/2015, fomos capazes de a um nível infraconstitucional (re)semantizar o princípio do contraditório, abandonando sua perspectiva meramente formal, como a noção de bilateralidade de audiência ou de paridade de armas, a noção cooperativa ganha sentido, adequando-se ao comando já presente na Constituição de $1988 .{ }^{30}$

É fato que o paradigma de processo trazido pelo $\mathrm{CPC} / 73$ desde muito já não era capaz de atender às necessidades da sociedade. Um problema comumente apontado pelos processualistas era a ausência de tratamento adequado para os casos que envolviam os

Advogado, 2010. (Coleção 0 que é Isto? - v. I). Nesse sentido lembra Streck, noutro texto, decisão que ilustra bem os perigos do solipsismo do "livre convencimento": "O sistema normativo pátrio utiliza o princípio do livre convencimento motivado do juiz, o que significa dizer que o magistrado não fica preso ao formalismo da lei nem adstrito ao laudo pericial produzido nos autos, devendo o julgador analisar o caso concreto, levando em conta sua livre convicção pessoal".

29 OMMATI, José Emílio Medauar. A fundamentação das decisões jurisdicionais no projeto do Novo Código de Processo Civil. In: FREIRE, Alexandre; DANTAS, Bruno; NUNES, Dierle; DIDIER JR., Fredie et al. Novas tendências do processo civil: estudos sobre o projeto do Novo Código de Processo Civil. Salvador: JusPodivm, 2014. v. III. p. 108.

30 NUNES, Dierle. Processo jurisdicional democrático: uma análise crítica das reformas processuais. Curitiba: Juruá, 2008. 
chamados litígios de massa, já diagnosticados por Cappelletti, no curso da década de $1970 .{ }^{31}$ Outro, é o fato de o CPC/73 adotar como pano de fundo a chamada teoria relacionista do processo, inaugurada por Bülow ${ }^{32}$ no século XVII e divulgada pelo pensamento de Liebman, Dinamarco, Grinover, Cintra e outros. Tal teoria tem por base a implementação de um modelo processual apoiado no solipsismo judicial, no qual ao magistrado é atribuída uma constelação de poderes e faculdades para controlar o processo, acabando por assumir uma posição de superioridade sobre os demais partícipes da dinâmica processual (autor, réu, advogados, Ministério Público, entre outros). Sabe-se hoje, principalmente a partir dos estudos de Fazzalari, ${ }^{33}$ que redefiniu os conceitos de processo e de procedimento, que tal aporte teórico é inadequado para um Estado que se autodenomine "democrático".

Esse novo modelo teórico influencia sobremaneira a temática da fundamentação das decisões judiciais - bem como o devido tratamento aos princípios constitucionais processuais do contraditório, da ampla defesa, da isonomia, do devido processo -, a despeito da exigência constitucional contida no art. 93, X, da Constituição de 1988. Não obstante a exigência normativa inaugurada pela Carta Magna, que consagrou um modelo principiológico de processo, conforme lição de Andolina e Vignera ${ }^{34}$, a práxis forense ainda não rompeu para com o modelo anterior.

Assim, o CPC/2015 não se limita a ampliar os participantes no processo, mas inclui o reconhecimento de que o ordenamento é interpretado e concretizado também fora dos Tribunais, e que o seu sentido é produzido por meio de debates que ocorrem em todos os locais em que existe o exercício da cidadania. Por este motivo, estabelece novos marcos teóricos para o direito processual civil brasileiro, recepcionando os princípios constitucionais processuais com nítidas alterações de concepção e de semântica, conforme se depreende do teor do art. $7^{\circ}$, art. 10 e art. 11. No que toca ao dever judicial de fundamentação dos provimentos, dispõe o art. 489, do novo Código de Processo Civil:

Art. 489. São elementos essenciais da sentença: I - o relatório, que conterá os nomes das partes, a identificação do caso, com a suma do pedido e da contestação, bem como o registro das principais ocorrências havidas no andamento do processo; II - os fundamentos, em que o juiz analisará as questões de fato e de direito; III - o dispositivo, em que o juiz resolverá as questões

${ }^{31}$ CAPPELLETTI, Mauro; GARTH, Bryant. Acesso à justiça. Porto Alegre: Fabris, 1988.

32 BÜLOW, Oskar Von. Gesetz und richteramt. Juristiche Zeitgeschichte. Berlim: Berliner Wissenschafts, 2003.

${ }^{33}$ FAZZALARI, Elio. Istituzioni di diritto processuale. 8. ed. Pádua: Cedam, 1996.

${ }^{34}$ ANDOLINA, Ítalo; VIGNERA, Giuseppe. II modelo costituzionale del processo civile italiano - corso di lesioni. Torino: Giappichelli, 1990. 

DWORKIN PODE FAZER CONTRA A TESE DO LIVRE CONVENCIMENTO MOTIVADO DO MAGISTRADO?

principais que as partes the submeterem. $\S 1^{\circ}$ Não se considera fundamentada qualquer decisão judicial, seja ela interlocutória, sentença ou acórdão, que: I se limitar à indicação, à reprodução ou à paráfrase de ato normativo, sem explicar sua relação com a causa ou a questão decidida; II - empregar conceitos jurídicos indeterminados, sem explicar o motivo concreto de sua incidência no caso; III - invocar motivos que se prestariam a justificar qualquer outra decisão; IV - não enfrentar todos os argumentos deduzidos no processo capazes de, em tese, infirmar a conclusão adotada pelo julgador; V - se limitar a invocar precedente ou enunciado de súmula, sem identificar seus fundamentos determinantes nem demonstrar que o caso sob julgamento se ajusta àqueles fundamentos; VI - deixar de seguir enunciado de súmula, jurisprudência ou precedente invocado pela parte, sem demonstrar a existência de distinção no caso em julgamento ou a superação do entendimento. $\S 2^{\circ}$ No caso de colisão entre normas, o juiz deve justificar o objeto e os critérios gerais da ponderação efetuada, enunciando as razões que autorizam a interferência na norma afastada e as premissas fáticas que fundamentam a conclusão. $\S 3^{\circ} \mathrm{A}$ decisão judicial deve ser interpretada a partir da conjugação de todos os seus elementos e em conformidade com o princípio da boa-fé.

Deve-se chamar a atenção para o fato de que falar em uma fundamentação da decisão adequada às balizas democráticas é, antes de tudo, exigir que a mesma leve a sério os argumentos, teses, provas de ambas as partes, visto que as mesmas participaram cooperativamente, em contraditório, na co-construção do provimento judicante. Disso decorre uma consequência fundamental - uma decisão fundamentada somente poderá ser aquela que, observando a legitimidade, busca se afirmar como "a correta" e que respeita o ideal de Dworkin para a integridade do Direito.

O norte-americano Ronald Dworkin é, reconhecidamente, um dos mais importantes e mais lidos autores contemporâneos nos campos do conhecimento jurídico, político e filosófico. Seu traço fundamental é a defesa da virtude da integridade (um ideal para nortear as práticas jurídico-políticas de uma sociedade, preocupado com o compromisso em dar às práticas do Legislativo e do Judiciário a melhor orientação e leitura possíveis). ${ }^{35}$ Também se tornou conhecido pelas duras críticas às tradições do Positivismo Jurídico e do Realismo Jurídico, ${ }^{36}$ bem

\footnotetext{
35 “Temos dois princípios de integridade política: um princípio legislativo, que pede aos legisladores que tentem tornar o conjunto de leis moralmente coerente, e um princípio jurisdicional, que demanda que a lei, tanto quanto possível, seja vista como coerente nesse sentido" (DWORKIN, Ronald. O Império do Direito. Trad. Jefferson Luiz Camargo. São Paulo: Martins Fontes, 1999. (Direito e Justiça). p. 213).

${ }^{36}$ Há juristas que discordem da utilização de Dworkin como marco teórico para pesquisas nacionais. Argumentam que a diferença de tradição que se estabelece entre os países do Common Law (de origem anglo-saxã) e os países do eixo Romano-Germânico (como o caso da França, Alemanha, Portugal, Espanha, além de outros, incluindo o Brasil) é abissal. Todavia, fato é que os traços fundamentais entre ambas as tradições, como destaca Ramires (RAMIRES, Maurício. Crítica à Aplicação de Precedentes no Direito Brasileiro. Porto Alegre: Livraria do Advogado, 2010. p. 62-63), parecem linhas cada vez mais tênues. Em "ecletismo", parece misturar as características principais e obscurecer distinções. Aliado a isso, deve-se lembrar que Dworkin não elabora em suas obras uma teoria exclusivamente voltada para o Common Law,
} 

DWORKIN PODE FAZER CONTRA A TESE DO LIVRE CONVENCIMENTO MOTIVADO DO MAGISTRADO?

FLÁVIO QUINAUd PEDRON

como por desenvolver uma teoria deontológica acerca dos princípios jurídicos, entendidos como espécies de normas jurídicas.

Dworkin obteve atenção da comunidade jurídica, inicialmente, quando publicou, na década de 1960, os primeiros textos atacando o Positivismo Jurídico, principalmente a leitura do inglês H. L. A. Hart. ${ }^{37}$ A tese central defendida por Dworkin, nesse ponto, é que o Positivismo Jurídico representa uma leitura do Direito incompatível com os pressupostos e anseios de uma sociedade que se quer democrática. Isso se deve, principalmente, pelo fato de se basear em uma defesa radical da separação entre Direito e Moral, que faz com que o Direito seja reduzido apenas a um conjunto de regras criadas por uma comunidade jurídica em um determinado momento da História. Assim, todo o problema de interpretação se limita a uma questão fáticohistórica: saber o que tal comunidade pretendia no momento de definição da regra positivada. ${ }^{38}$ Por consequência, um juiz positivista tem seu trabalho limitado a identificar, nos casos a ele submetidos para julgamento, a partir de um raciocínio silogístico, quais as regras se amoldam aos fatos do litígio e aplicar, tomando o sentido estabelecido no passado, tais regras.

As falhas nessa teoria começam a aparecer quando esse mesmo juiz não é capaz de encontrar regras previamente elaboradas para aplicação e, com isso, solução dos casos sub judice. Temos aqui a distinção de Hart entre casos fáceis e os casos difíceis. No último caso, temos a presença de uma lacuna (ou anomia) no Ordenamento Jurídico. Em tal cenário, a solução encontrada pelo Positivismo Jurídico é uma só: autorizar ao mesmo magistrado que promova um julgamento discricionário; ou seja, o mesmo estará agora autorizado a utilizar sua consciência e seu senso de justiça para decidir de modo unilateral o caso concreto. ${ }^{39}$ Com isso, estar-se-á admitindo ao magistrado criar direito novo e aplicá-lo retroativamente ao caso concreto, surpreendendo as partes do processo.

mas antes, uma teoria geral do direito, aplicável a qualquer perspectiva ocidental. Ele se preocupa em apresentar uma proposta reconstrutiva da prática jurídica ancorada nas conquistas da hermenêutica filosófica, de um lado, e na preocupação com a legitimidade das decisões jurídicas, de outro. Tal tema é universal; logo, faz com que suas ideias ganhem espaço de reflexão e aplicação para os juristas brasileiros, e não apenas norte-americanos.

${ }^{37}$ H.L.A. Hart é autor da obra $O$ Conceito de Direito (Tradução de A. Ribeiro Mandes. Lisboa: Fundação Calouste Gulbenkian, 1994) na qual expõe uma das mais bem estruturadas e sofisticadas versões dessa tradição.

${ }^{38}$ A definição de como tais regras são criadas não se prende exclusivamente ao modelo de uma atividade legislativa, reconhecendo Hart que o judiciário (principalmente quando define um precedente) também tem um papel político como órgão criador (ou descobridor) de regras jurídicas, sendo igualmente responsável por tal positivação.

39 Igual crítica a tal discricionariedade judicial pode ser encontrada em STRECK, Lenio Luiz. 0 que é isto decido conforme minha consciência? Porto Alegre: Livraria do Advogado, 2010. (Coleção O que é Isto? - v. I) 
Dworkin entende que tal quadro, pintado pela teoria positivista, é pobre e não reflete as cores do que uma sociedade democrática chama de Direito. Ou seja, que é possível pensar uma outra teoria jurídica mais atraente para os ideais de democracia da sociedade. ${ }^{40}$ Imagina, então, que a noção que parece tão clara aos positivistas de que o magistrado tem discricionariedade para decidir os casos difíceis é uma incoerência, quando contraposta ao ideal democrático.

Para combater o quadro positivista, Dworkin parte de dois raciocínios paralelos (mas que se complementam ao final): (1) de que não pode existir tal discricionariedade, e para fazer tal afirmação, ele necessariamente deverá afirmar que todo aquele responsável por uma decisão jurídica (seja o legislador, seja o magistrado, seja um administrador público) deve se comprometer moralmente para com a sociedade em não poupar esforços para buscar a melhor decisão para aquela situação (isso significa afirmar que ao invés de haver múltiplas possibilidades de decisão, ainda que entre elas haja racionalidade, há apenas "uma única decisão correta" para aquele caso em especial); e (2) de que além das regras jurídicas, o Ordenamento Jurídico deve apresentar outras espécies de normas, capazes de impedir por completo a existência de uma lacuna e, assim, conseguir definir naquele caso sub judice a existência de um direito para alguma das partes envolvidas.

Vamos primeiro em (1). Para qualquer um de nós, pode parecer absurdo, sob o pano de fundo democrático, a ideia de que um magistrado tem total liberdade para decidir um caso. Dois argumentos são levantados para negar a possibilidade de discricionariedade de decisões judiciais: (a) o governo é limitado pela responsabilidade de seus ocupantes, que são eleitos pela maioria; e (b) criando um direito novo, o juiz pune injustamente a parte sucumbente, uma vez que o aplica de forma retroativa.

Afirmar e defender a discricionariedade equivaleria, então, a concordar com a frase dos Realistas Jurídicos de que os juízes decidem baseados naquilo que comeram no café da manhã. ${ }^{41}$ Mas contra ela, diversas versões do Positivismo Jurídico desenvolveram a tese de que, sendo o direito produto de homens (e não uma ciência exata), não seria possivel afirmar a existência de uma única resposta correta, mas antes um universo de possíveis (racionais) decisões. Só que o

\footnotetext{
${ }^{40}$ Perceba a ênfase que Dworkin está dando para a ideia de que nossa sociedade é democrática (ou quer ser assim chamada) e está disposta a assumir tal virtude de braços abertos. Essa conclusão é importante: aquele que levanta objeções à proposta elaborada por Dworkin corre sério risco de assumir-se ou como um positivista jurídico, ou, pior, como um jurista não comprometido com a busca pela construção de uma sociedade democrática (o que está no próprio texto e na base ideológica da Constituição de 1988, art. $1^{\circ}$, caput)

41 Endossam essa leitura: HOLMES, Oliver Wendell. The Common Law. Boston: Little \& Brown, 1881; FRANK, Jerome. Law and the Modern Mind. New York: Brentano's, 1930.
} 

DWORKIN PODE FAZER CONTRA A TESE DO LIVRE CONVENCIMENTO MOTIVADO DO MAGISTRADO?

FLÁVIO QUINAUd PEDRON

raciocínio e a argumentação jurídica apenas serviriam para filtrar as aberrações, elaborando uma moldura de decisões jurídicas racionais (portanto, para eles, legítimas). ${ }^{42} \mathrm{E}$ qualquer coisa que estivesse dentro de tal moldura seria legítima ainda que não representasse o melhor esforço para solucionar normativamente o caso.

Dworkin entende como simplesmente pobre esse raciocínio. Em oposição, advoga ideia de que ninguém - pondo-se na condição de destinatário da decisão - aceitaria como razoável a afirmação de que seu caso foi tratado pelo Judiciário como apenas mais um, e que mesmo aquela não sendo uma decisão fruto do raciocínio mais elaborado e comprometido do magistrado, se trataria de uma decisão possível. ${ }^{43}$ Ou que o resultado do processo é fruto de uma loteria aleatória, de modo que o caso poderia receber uma decisão completamente diferente se tivesse sido julgado por outro magistrado.

A virtude da integridade afirma que todos nós temos um direito (que apresenta uma das subdivisões daquilo que o jurista norte-americano designa por Dignidade Humana ${ }^{44}$ ) de sermos tratados com igual respeito e consideração. Desse modo, repercutiria um dever de o Judiciário levar o caso a sério e tratá-lo com cuidado.

Para se fazer mais claro, Dworkin usa uma figura de linguagem, um juiz imaginário (e não um método de decisão) para exemplificar a postura que uma sociedade democrática espera dos magistrados. ${ }^{45}$ Ele batiza essa metáfora de juiz Hércules, de modo que ele é capaz de usar sua sabedoria e paciência para buscar a resposta correta para suas sentenças. Seu magistrado, então, terá que ao decidir levar em conta todos os argumentos trazidos pelas partes no

\footnotetext{
42 Mas o problema de afirmar a possibilidade de uma moldura das decisões/interpretações possíveis já foi enfrentado por Kelsen (Teoria Pura do direito. 6. ed. Trad. João Baptista Machado. São Paulo: Martins Fontes, 1999. (Direito e Justiça)). Contudo, o jurista austríaco se viu encurralado em sua própria construção teórica, tendo que admitir como igualmente jurídicas decisões fora da moldura normativa - ou seja: ilegítimas, inconstitucionais, antidemocráticas ou padecendo de qualquer outro vício jurídicopolítico, pura e simplesmente porque o Judiciário tem o poder coercitivo para fazer cumprir tal decisão.

${ }^{43}$ Tem por hábito imaginar que decisões judiciais pressupõem um comprometimento moral de todos os envolvidos no processo de decisão e que, por isso, há um esforço normativo, implícito para que não seja apenas uma decisão, mas a melhor decisão possível. O processo de elaboração de uma sentença não pode ser comparado com o ato de escolher que cacho de bananas alguém levará para casa depois da feira, até porque ninguém escolhe qualquer cacho para comprar! Buscamos sempre o melhor em tudo o que fazemos e mostra-se incoerente esperar do Judiciário uma postura diferente.

${ }^{44}$ DWORKIN, Ronald. Justice for Hedgehogs. Harvard: Harvard University, 2011.

45 É comum a interpretação equivocada de que o juiz Hércules é impossível de ser imitado. Dworkin como um hermeneuta e filiado ao pensamento de Gadamer (Verdade e Método: Fundamentos de uma hermenêutica filosófica. 7. ed. Trad. Enio Paulo Giachini. Petrópolis: Vozes, 2005) não acredita na intuição positivista (científica) de que a verdade somente pode ser descoberta (ou desvelada) a partir de uma perspectiva controlada por uma experiência científica garantida por um método. A pretensão em afirmar com Gadamer que a verdade não é uma construção universal (única e imutável) parece ser desconhecida pelos críticos de Dworkin, principalmente no Brasil. Hércules é, então, apenas um exercício didático do que significa uma postura esperada pela sociedade dos seus juízes.
} 

DWORKIN PODE FAZER CONTRA A TESE DO LIVRE CONVENCIMENTO MOTIVADO DO MAGISTRADO?

FLÁVIO QUINAUd PEDRON

processo, bem como tudo aquilo que foi construído do ponto de vista probatório-fático. Mas isso não basta, Hércules irá também procurar reconstruir a história institucional para verificar como os outros juízes decidiram no passado casos semelhantes, ampliando o diálogo processual para justificar em sua decisão essa história.

Mas diferente dos juízes positivistas, Hércules não está preso no passado e não é obrigado a seguir as decisões se verificar que há erros em algumas delas; contudo, ele se sente obrigado moralmente a seguir os precedentes que se mostrarem coerentes. Esses precedentes sinalizam a existência de uma história em movimento, uma história do próprio direito que se está sendo discutido no caso que ele deve decidir. Essa obrigação hermenêutica faz com que o magistrado de Dworkin se coloque como um membro de um empreendimento coletivo, uma história (a história daquele direito em especial) que está sendo contada e construída a várias mãos. A responsabilidade de Hércules, portanto, o leva a ler e a levar em conta tudo aquilo que foi escrito e decidido acerca do direito envolvido.

A partir disso, Hércules fará sua parte - ou seja, ele será responsável por adicionar um novo capítulo desenvolvendo a discussão, sem ignorá-la ou sem reinventá-la. ${ }^{46}$ Para tanto, deve se basear na ideia de que sua decisão (jurídica e moralmente) deve considerar que todas as pessoas da sociedade têm os mesmos direitos e liberdades, sem privilégios e, principalmente, sem discriminações baseadas em preconceitos de qualquer espécie (religiosos, filosóficos, econômicos, políticos, etc.). Essa última exigência faz com que a virtude da integridade seja vista de modo diferente da mera coerência (ou seja, mera repetição do passado).

O desafio posto para Hércules é reconhecer o direito como algo criado por meio de leis, mas, igualmente, seguir as decisões que o próprio Judiciário tomou no passado. Isso o levará a construir um sistema baseado em princípios jurídicos capaz de fornecer a melhor justificativa para os precedentes judiciais, e também para as leis e para a Constituição.

A decisão que, ao final, Hércules chegará não é dele exclusivamente. A abertura hermenêutica exigiu um diálogo com as partes do processo e com a história daquela sociedade, além de preservar condições para que os próximos juízes, nos próximos casos, continuem o

\footnotetext{
46 Dworkin (Uma Questão de Princípio. 2. ed. Trad. Luís Carlos Borges. São Paulo: Martins Fontes, 2005. (Direito e Justiça).) compara essa tarefa a uma brincadeira infantil na qual cada participante é responsável por contar um única história. Na brincadeira, todos os participantes têm o mesmo tempo para participar e devem ouvir atentamente os antecessores para que uma linha de coerência entre a história contada seja preservada. Não se trata de um "telefone sem fio", pois o objetivo da brincadeira não é repetir o que foi transmitido, mas desenvolvê-lo (evoluí-lo) da melhor forma, preservando os elementos essenciais do que inicialmente foi definido. Ou seja, se o primeiro a contar a história teve o objetivo de narrar um suspense, o participante da sequência deve ter a capacidade hermenêutica de perceber que ele não poderá transformar agora aquilo em uma comédia.
} 

DWORKIN PODE FAZER CONTRA A TESE DO LIVRE CONVENCIMENTO MOTIVADO DO MAGISTRADO?

FLÁvio QUINAUd PEDRON

empenho de melhorar a decisão. ${ }^{47}$ É isso que Dworkin quer dizer quando fala em única resposta correta (ou na melhor decisão judicial). Percebe-se aqui que o espaço de discricionariedade é eliminado para dar lugar a um espaço hermenêutico e argumentativo. Hércules deve tentar convencer a sociedade que confiou aquele caso ao seu julgamento que fez o melhor que podia. Isso não tem como ser feito sem que estejamos dispostos a fundamentar adequadamente a decisão. ${ }^{48}$

Agora se pode avançar para (2). Para contrapor a tese da redução do direito a um sistema de regras, bem como a afirmação de que existem lacunas do sistema jurídico, Dworkin ${ }^{49}$ afirmará que, para além das regras ${ }^{50}$, dois outros padrões de normas existem (os princípios e as diretrizes políticas). Essa separação em três espécies de normas não se apoia em uma distinção estrutural ou morfológica, mas sim, em uma questão lógico-argumentativa, pois no debate é que se pode entender se o que está sendo invocado representa uma regra, um princípio ou uma diretriz política.

Assim, analisando a relação entre princípios e diretrizes políticas, pode-se afirmar que um princípio prescreve um direito e, por isso, contém uma exigência de justiça, equanimidade, devido processo legal, ou a qualquer outra dimensão de moralidade ${ }^{51}$; ao passo que uma diretriz política estabelece um objetivo ou uma meta a serem alcançados, os quais geralmente consistem na melhoria de algum aspecto econômico, político ou social da comunidade, buscando promover ou assegurar uma situação econômica, política ou social considerada desejável. Dworkin atribui o status de trunfos aos princípios, que, em uma discussão, devem sobrepor-se a argumentos pautados em diretrizes políticas, excluindo a possibilidade de os juízes tomarem decisões embasadas em diretrizes políticas. Esse raciocínio marca a posição antiutilitarista assumida por Dworkin, de modo a rejeitar qualquer forma de males feitos aos indivíduos em

\footnotetext{
${ }^{47}$ THEODORO JR, Humberto; NUNES, Dierle; BAHIA, Alexandre; PEDRON, Flávio. Novo CPC: Fundamentos e Sistematização. 3. ed. Rio de Janeiro: Forense, 2016.

48 THEODORO JR, Humberto; NUNES, Dierle; BAHIA, Alexandre; PEDRON, Flávio. Novo CPC: Fundamentos e Sistematização. 3. ed. Rio de Janeiro: Forense, 2016.

49 DWORKIN, Ronald. Levando os Direitos a Sério. Trad. Nelson Boeira. São Paulo: Martins Fontes, 2002. (Direito e Justiça).

${ }^{50}$ Deve-se alertar para o fato de que as traduções para a língua espanhola utilizam o termo normas como sinônimo de regras jurídicas, como faz Calsamiglia (CALSAMIGLIA, Albert. El Concepto de Integridad en Dworkin. Doxa, n. 12, 1992. p. 168-169), o que acaba por induzir à ideia errônea de que princípios não são normas jurídicas, mas sim ligados ao chamado Direito Natural.

${ }^{51}$ Moralidade aqui significa afirmar o dever do direito em garantir a dignidade humana e o respeito aos mesmos direitos e liberdades subjetivas.
} 
favor de uma melhoria para o bem-estar geral ou uma leitura de direito a partir da ótica do custo-benefício. ${ }^{52}$

Essa atividade jurisdicional, então, tem que abraçar a afirmação de que é possível uma resposta correta para o julgamento de um dado caso particular, o que significa aplicar o princípio adequado ao caso concreto - assim conecta-se (1) com (2) em nosso raciocínio. Ora, uma vez que Dworkin reconhece a existência de princípios que podem prover soluções para os litígios, ele nega uma das teses básicas do positivismo jurídico, que a existência de lacunas normativas autoriza o magistrado a agir discricionariamente ao criar uma norma, e aplicá-la retroativamente.

Logo, a "função criativa" do Judiciário para os casos difíceis, defendida pelos positivistas e pela TGP brasileira, é rechaçada por Dworkin, que compreende que apenas o legislador é autorizado a criar direito. 0 debate sobre a fixação de uma diretriz política tem que ser exercido de forma mais abrangente para incluir um número maior de participantes, levando em conta os diferentes interesses antagônicos e, por isso, somente pode ser tomada no interior de um processo legislativo.

Já a decisão baseada por princípios faz uso da história institucional daquela comunidade e coloca, ao mesmo tempo, limite e condição de possibilidade de construção de uma decisão democrática. ${ }^{53}$ Nesse sentido, tem-se que, ao final do processo, o provimento jurisdicional encontra-se fundamentado, apontando a decisão correta para aquele caso sub judice, uma vez que sua construção observou, de um lado, exigências processuais democráticas, como o contraditório substancial; e de outro, normativas hermenêuticas voltadas para o respeito e desenvolvimento da integridade do Direito.

\section{CONCLUSÃO}

Ao longo da presente discussão, procurou-se deixar clara a conexão que há entre a afirmação de uma tese do livre convencimento motivado por parte dos magistrados e uma adesão a uma tradição positivista jurídica, de um lado, e, de outro, a uma leitura que ainda

\footnotetext{
52 THEODORO JR, Humberto; NUNES, Dierle; BAHIA, Alexandre; PEDRON, Flávio. Novo CPC: Fundamentos e Sistematização. 2. ed. Rio de Janeiro: Forense, 2015.

53 “Um argumento de princípio pode oferecer uma justificação para uma decisão particular, segundo a doutrina da responsabilidade, somente se for possível mostrar que o princípio citado é compatível com decisões anteriores que não foram refeitas, e com decisões que a instituicão está preparada para tomar em circunstâncias hipotéticas" (DWORKIN, Ronald. Levando os Direitos a Sério. Trad. Nelson Boeira. São Paulo: Martins Fontes, 2002. (Direito e Justiça). p. 138).
} 
impregna a Teoria Geral do Processo, que, a despeito de todas as transformações impostas pelo paradigma democrático, ainda tenta manter viva uma concepção relacionista/instrumentalista de processo.

Ora, somente sob tais balizas - desprezando absolutamente as normativas democráticas - que se mostra possível afirmar uma discricionariedade jurisdicional, muitas vezes mascarada sob a forma de uma afirmação de possibilidade (ainda que falaciosa) de um livre convencimento - ainda que meramente motivado - jurisdicional.

O curioso é que mesmo aqueles que assumem uma redução do dever constitucional (art. 93, IX da (F/88) a uma motivação - quer por ignorância epistêmica, quer por perversidade ideológica, como diria Calmon de Passos $^{54}$-, fazem-no desprezando exigências normativas democráticas - que não são opcionais, nem estão à disposição do magistrado.

Desta forma, apenas através da assunção de um paradigma verdadeiramente democrático é que se faz possível afirmar a possibilidade de superação das arcaicas amarras que prendem os juristas brasileiros tradicionais a uma TGP que acredite em uma teoria relacionista do processo (ou sua versão instrumentalista), ou aceita o manto do Positivismo Jurídico.

Um caminho possível é exatamente através da teoria do direito como integridade desenvolvida por Dworkin, já que esta, além de se fazer consciente de uma dimensão hermenêutica pós giro linguístico, também leva em conta a tônica de uma teoria preocupada com a necessidade de efetivação da dimensão normativa-democrática. A partir dessa teoria, mostra-se possível a superação da tese do livre convencimento motivado, afirmando e explicando a concretude de uma teoria que atesta a possibilidade de uma verdadeira fundamentação dos provimentos, conforme explicado acima.

\section{REFERÊNCIAS}

ABBOUD, Georges. Discricionariedade: alcance da atuação administrativa e judicial no Estado Constitucional. 2013. Tese (Doutorado em Direito) - Pontifícia Universidade Católica de São Paulo, São Paulo, 2013.

ALISTE SANTOS, Tomás- Javier. La motivación de las resoluciones judiciales. Madrid: Marcial Pons, 2011.

${ }^{54}$ CALMON DE PASSOS, J. J. Instrumentalidade do Processo e Devido Processo sobre o tema. In: FIUZA, César; SÁ, Maria de Fátima Freire de; BRÊTAS, Ronaldo (Coord.). Temas Atuais de Direito Processual Civil. Belo Horizonte: Del Rey, 2001. p. 24. 
ANDOLINA, Ítalo; VIGNERA, Giuseppe. II modelo costituzionale del processo civile italiano corso di lesioni. Torino: Giappichelli, 1990.

ASSUMPÇÃO NEVES, Daniel Amorim. Manual de direito processual civil. São Paulo: Método, 2009.

BUENO, Cassio Scarpinella. Curso Sistematizado de Direito Processual Civil: Teoria Geral do Direito Processual Civil. 7. ed. São Paulo: Saraiva, 2013. v. 1.

BÜLOW, Oskar Von. Gesetz und richteramt. Juristiche Zeitgeschichte. Berlim: Berliner Wissenschafts, 2003.

CALAMANDREI, Pietro. Eles os juízes, vistos por nós um advogado. São Paulo: Martins Fontes, 1995.

CALMON DE PASSOS, J. J. Instrumentalidade do Processo e Devido Processo sobre o tema. In: FIUZA, César; SÁ, Maria de Fátima Freire de; BRÊTAS, Ronaldo (Coord.). Temas Atuais de Direito Processual Civil. Belo Horizonte: Del Rey, 2001.

CALSAMIGLIA, Albert. El Concepto de Integridad en Dworkin. Doxa, n. 12, 1992.

CAPPELLETTI, Mauro; GARTH, Bryant. Acesso à justiça. Porto Alegre: Fabris, 1988.

CARNELUTTI, Francesco. Diritto e processo. Napoli: Morano, 1958.

CINTRA, Antônio; GRINOVER, Ada; DINAMARCO, Cândido. Teoria Geral do Processo. 19. ed. São Paulo: Malheiros, 2003.

DIDIER JR., Fredie; BRAGA, Paula Sarno; OLIVEIRA, Rafael Alexandria. Curso de Direito Processual Civil. 11. ed. Salvador: JusPodivm, 2016. v. 2.

DINAMARCO, Cândido Rangel. A Instrumentalidade do Processo. 14. ed. São Paulo: Malheiros, 2009.

DWORKIN, Ronald. Justice for Hedgehogs. Harvard: Harvard University, 2011.

DWORKIN, Ronald. Levando os Direitos a Sério. Trad. Nelson Boeira. São Paulo: Martins Fontes, 2002. (Direito e Justiça).

DWORKIN, Ronald. O Império do Direito. Trad. Jefferson Luiz Camargo. São Paulo: Martins Fontes, 1999. (Direito e Justiça).

DWORKIN, Ronald. Uma Questão de Princípio. 2. ed. Trad. Luís Carlos Borges. São Paulo: Martins Fontes, 2005. (Direito e Justiça).

FAZZALARI, Elio. Istituzioni di diritto processuale. 8. ed. Pádua: Cedam, 1996.

FERNANDES, Bernardo Gonçalves; PEDRON, Flávio Quinaud. O Poder Judiciário e $(\mathrm{m})$ Crise. Rio de Janeiro: Lumen Juris, 2008. 
FRANK, Jerome. Law and the Modern Mind. New York: Brentano's, 1930.

GADAMER, Hans-Georg. Verdade e Método: Fundamentos de uma hermenêutica filosófica. 7 ed. Trad. Enio Paulo Giachini. Petrópolis: Vozes, 2005.

HART, H. L. A. O Conceito de Direito. Trad. A. Ribeiro Mandes. Lisboa: Fundação Calouste Gulbenkian, 1994.

HESSE, Konrad. A força normativa da Constituição. Trad. Gilmar Ferreira Mendes. Porto Alegre: Sergio Antonio Fabris, 1991.

HOLMES, Oliver Wendell. The Common Law. Boston: Little \& Brown, 1881.

KELSEN, Hans. Teoria Pura do direito. 6. ed. Trad. João Baptista Machado. São Paulo: Martins Fontes, 1999. (Direito e Justiça).

KUHN, Thomas S. A estrutura das revoluções científicas. 6. ed. Trad. Beatriz Vianna Boeira e Nelson Boeira. São Paulo: Perspectiva, 2001. (Coleção Debates, n. 115).

NUNES, Dierle. Processo jurisdicional democrático: uma análise crítica das reformas processuais. Curitiba: Juruá, 2008.

OMMATI, José Emílio Medauar. A fundamentação das decisões jurisdicionais no projeto do Novo Código de Processo Civil. In: FREIRE, Alexandre; DANTAS, Bruno; NUNES, Dierle; DIDIER JR., Fredie et al. Novas tendências do processo civil: estudos sobre o projeto do Novo Código de Processo Civil. Salvador: JusPodivm, 2014. v. III.

PEDRON, Flávio Quinaud. A distinção entre legislação e jurisdição no pensamento de Klaus Günther. Revista da CEJ, Brasília, ano XII, n. 41, abr./jun. 2008.

PEDRON, Flávio Quinaud. Mutação constitucional e crise do positivismo jurídico. Belo Horizonte: Arraes, 2012.

RAMIRES, Maurício. Crítica à aplicação dos precedentes no direito brasileiro. Porto Alegre: Livraria do Advogado, 2010.

SANTOS, Eduardo Rodrigues dos. Princípios Processuais Constitucionais. Salvador: JusPodivm, 2016.

SANTOS, Moacyr Amaral. Primeiras linhas de direito processual civil. 22. ed. São Paulo: Saraiva, 2008. v. 3.

SCHMITZ, Leonad Ziesemer. Fundamentar para Decidir: a crise na construção de respostas no processo civil. São Paulo: Revista dos Tribunais, 2015.

STRECK, Lenio Luiz. 0 que é isto: decido conforme minha consciência? Porto Alegre: Livraria do Advogado, 2010. (Coleção 0 que é Isto? - v. I)

TARUFFO, Michele. La Motivación de la Sentencía Civil. Trad. Lorenzo Córdova Vianello. Madrid: Trotta, 2011. 
THEODORO JR., Humberto; NUNES, Dierle; BAHIA, Alexandre; PEDRON, Flávio. Novo CPC:

Fundamentos e Sistematização. 3. ed. Rio de Janeiro: Forense, 2016.

ZUFELATO, Camilo. Fundamentação lógica das decisões judiciais. In: THEODORO JR., Humberto; CALMON, Petrônio; NUNES, Dierle (Coord.). Processo e Constituição. Rio de Janeiro: GZ, 2011.

\section{COMO FAZER A REFERÊNCIA DO ARTIGO (ABNT):}

PEDRON, Flávio Quinaud. Que críticas da teoria do direito como integridade de Dworkin pode fazer contra a tese do livre convencimento motivado do magistrado? Revista Eletrônica do Curso de Direito da UFSM, Santa Maria, RS, v. 13, n. 2, p. 754-774, ago. 2018. ISSN 1981-3694. Disponível em: <https://periodicos.ufsm.br/revistadireito/article/view/30920>. Acesso em: dia mês. ano. doi: http://dx.doi.org/10.5902/1981369430920. 